\section{Why doctors must grapple with health economics}

Medical journals are publishing more and more articles that report on not just the medical but also the economic consequences of treatment. The main constraints on health care are now more financial than medical or technical, and the separation of clinical judgment from financial responsibility will soon end-clinical budgeting, for example, is just around the corner. More doctors are becoming formal managers, and their medical ethics will conflict with their new status. Increasingly doctors will have to take decisions with an economic component, and therefore they must be able to understand and critically evaluate papers that contain health economics.

On p 339 Olsson and others present the economic consequences of using a $\beta$ blocker, metoprolol, for prophylaxis after myocardial infarction. Their conclusion is that such treatment seems cost effective. They observed over three years that patients treated with metoprolol were on average healthier than patients treated with a placebo and that their treatment cost less in terms not only of health care (direct costs) but also of days off work and early retirement (lost production or indirect costs). The short term economic message is that using metoprolol in this way saves money both for the health care agencies and "society." This straightforward message should, however, be read with reservation. In this short space I cannot give a comprehensive critique of the paper, but examples are raised of specific questions that should be addressed by any cost effectiveness analysis. (More detailed expositions of health economics are available elsewhere. ${ }^{1-4}$ )

Most, if not all, economic studies rely on the robustness and integrity of the underlying medical study. The final message of the metoprolol paper must be read in the light of answers to questions such as: Were the sizes of control and trial groups adequate? Was the follow up long enough? In brief, the usual criteria for establishing proof of effectiveness need to be applied. The metoprolol study has three medical aspects that directly affect the economic analysis: sickness leave and early retirement (indirect costs); hospital costs (direct costs); and health outcome. A much longer study might show a change in the results and partly or wholly reverse the authors' economic conclusions. The lack of data makes it risky to extrapolate from the three year results. No refinement in the economic analysis can eradicate doubts about the long term effects of metoprolol. This does not invalidate the study, and the authors take care to mention the uncertain effects of treatment with metoprolol beyond the three years, but it does muddy the waters for taking a clear cut economic decision on whether to use metoprolol.

The dangers of extrapolating the authors' results arise from the possibility that in the long term the longer survival rates of patients treated with metoprolol will increase hospital costs. This comes perilously close to stating that euthanasia is the only valid medical action on economic grounds. This conclusion, rightly rejected by the authors, is based on the false premise that the only criterion that a cost effectiveness analysis promulgates is cost minimisation. Cost minimisation has a logical validity only when constrained by the desire to achieve positive health benefits. Early death-while cheap for the health service-is not usually considered one of the goals of medical intervention. The study's economic analysis reflects this by including indirect costs, which as well as representing some notional loss of productivity place in crude sense an economic value on health outcome.

Economic analysis is an art requiring assumptions an proxies. In its imperfect way cost effectiveness analysis attempts to bridge the difficult gap between the inevitab use of scarce resources and the benefits that flow from treatment or service. Cost effectiveness analysis should not be seen as having the power of veto but rather as providin one part of the information (in addition to political, socia? medical, and philosophical criteria) necessary to achieve $\$$ truly informed decision about using society's resources.

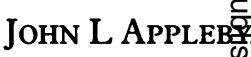

District Health Economist,

South Birmingham Health Authority,

Birmingham B29 6JF

1 Drummond MF. Principles of ecomomic appraisal in health care. Oxford: Oxford Univers

1980.
2 Drummond MF. Studies in economic appraisal in health care. Oxford: Oxford University Preß8

3 Blades CA, Cuyler AJ, Wiseman J, Walker A. The intermational bibliography of health economics comprehensive guide to English language studies since 1914. Brighton: Wheatsheaf Books, 1986. Mooney GH, Drummond MF. Essentials of health economics. Parts I-IV. Br Med F 1982;285 949-50, 1101-2, 1191-2, 1263-4, 1329-31, 1405-6, 1485-6, 1561-3, 1638-9, 1727-8.

\section{The third heart sound}

The third heart sound is a series of low frequency vibrationg in early diastole best heard with the bell of the stethoscope the cardiac apex. It is normal in children and young adults but usually disappears after 40 . It also occurs in patients with high cardiac output caused by anaemia, fever, pregnancy and thyrotoxicosis. If the patient is over 40 the third heani sound nearly always shows that something is wrong- $\frac{8}{0}$ usually left ventricular failure, but less commonly mitra regurgitation or constrictive pericarditis. The timing and quality of the third heart sound remain remarkably constant regardless of its cause-except in constrictive pericarditis, when the "pericardial knock" is early and high pitched.

The third heart sound is associated with rapid le ventricular filling, which occurs during relaxation of the ventricle in early diastole. When relaxation is almost ove filling decelerates abruptly. This deceleration is widely held to convert kinetic energy to vibratory energy, which if sufficiently vigorous causes the third heart sound. ${ }^{1-3}$ This theory has been challenged by Prewitt et al, who could fins no consistent relation between any aspect of rapid ventriculate filling and the timing of the third heart sound. ${ }^{4}$ The lef. ventricle is, however, ellipsoid and these investigators conclusions were based on measurements made in the transverse (short) axis; more recent work suggests the completion of long axis ventricular relaxation is the eveff that triggers the third heart sound. ${ }^{56}$

Van de Werf et al have emphasised that theories on the mechanism of the third heart sound must account for both if normal and abnormal occurrence. ${ }^{7}$ They found that the volume and velocity of inflow and the completeness of ventricular relaxation were important determinants deceleration during rapid ventricular filling. ${ }^{8}$ These observas tions readily account for the pathological third heart sound i patients with high cardiac output or mitral regurgitation both of which are associated with increased volume and 